\title{
SUERO AUTÓLOGO EN PATOLOGÍA OCULAR POR HIPOVITAMINOSIS
}

\section{USE OF AUTOLOGOUS SERUM IN HYPOVITAMINOSIS-INDUCED OCULAR PATHOLOGY}

\author{
BOSCH-VALERO J ${ }^{1}$, MARTÍN-AVIÁ J ${ }^{1}$, SIERRA-BARRERAS J ${ }^{1}$, RODRÍGUEZ-MARCO A ${ }^{1}$, \\ CRISTÓBAL-BESCÓS JA ${ }^{2}$
}

\section{RESUMEN}

Caso clínico: Se presentan dos casos de pacientes con el antecedente de haber sido sometidos a la intervención de Scopinaro, que presentan afectación corneal severa con dolor y deterioro de la agudeza visual en grado variable. Ambos se beneficiaron de un tratamiento a base de suero autólogo tópico con una mejoría que contrastaba con el deterioro de su estado nutricional.

Discusión: El suero autólogo tópico aporta a la superficie ocular factores de crecimiento y nutrientes necesarios para el trofismo celular de la cornea, siendo un tratamiento apropiado para la patología ocular carencial que puede ocurrir en pacientes desnutridos.

Palabras clave: Hipovitaminosis, suero autólogo, cirugía bariátrica, sequedad ocular, tretinoina.

\begin{abstract}
Case report: We present two case reports of patients suffering from severe corneal damage resulting in pain and visual impairment, after undergoing Scopinaro's operation. Both patients improved after treatment with topical autologous serum although their nutritional state became worse.

Discussion: Topical autologous serum provides growth factors and nutrients needed for corneal cell repair, and is appropriate treatment for carential ocular pathology which may accompany malnutrition (Arch Soc Esp Oftalmol 2007; 83: 45-48).
\end{abstract}

Key words: Hypovitaminosis, autologous serum, bariatric surgery, dry eye syndrome, tretinoin.

\section{INTRODUCCIÓN}

La cirugía bariátrica es una opción terapéutica en auge en la obesidad mórbida, cuyo objetivo es la reducción de la capacidad gástrica o la limitación del tramo intestinal efectivo para la absorción lipí- dica. La técnica de Scopinaro es de las más utilizadas y consiste en una gastrectomía parcial y un bypass biliopancreático. Esta cirugía no esta exenta de complicaciones como alteraciones del ritmo deposicional, neumonías, tromboflebitis y déficits vitamínicos.

\footnotetext{
Recibido: 26/1/06. Aceptado: 20/9/07.

Hospital Clínico Universitario Lozano Blesa. Zaragoza. España.

1 Licenciado en Medicina.

2 Doctor en Medicina.

Correspondencia:

Jordi Bosch Valero

Carrer de la Pampa, 17

07703 Mahón (Menorca)

España

E-mail: jordiperebosch@yahoo.es
} 
Oftalmológicamente, la carencia de vitamina A produce metaplasia escamosa (1), pérdida de células caliciformes (1), acortamiento de microvellosidades, microerosiones y adelgazamiento estromal en fases avanzadas. Está descrito que el ácido retinoico tópico revierte la metaplasia escamosa en la citología de impresión (1). El uso parenteral de complementos vitamínicos también ha sido utilizado con éxito en patología ocular carencial tras cirugía bariátrica (2).

El suero autólogo aporta factores de crecimiento y del complemento, fibronectina, IgG, lisozima, antiproteasas y vitamina $\mathrm{A}$, por lo que tiene múltiples indicaciones en la patología de la superficie ocular. Comparando los estudios de Speek (3) y Tsubota (4) se deduce que el retinol está 1.000 veces más concentrado en suero que en la lágrima, por lo que la preparación del suero autólogo a partir del mismo puede aportar vitamina A tópica en patología ocular carencial.

\section{CASO CLÍNICO}

Se presentan dos casos de afectación de la superficie ocular secundaria a hipovitaminosis $\mathrm{A}$, en pacientes intervenidos de obesidad mórbida mediante la técnica de Scopinaro.

\section{Caso 1}

Varón de 37 años con disminución visual bilateral, escozor y sensación de cuerpo extraño. Antecedentes de intervención de Scopinaro tres años atrás, con diversas complicaciones postoperatorias (tuberculosis pulmonar, neuropatía de extremidades, anemia y alteraciones gastrointestinales).

En la exploración se apreciaba palidez mucocutánea y debilidad general. En el área oftalmológica presentaba falta de brillo en la superficie ocular, disminución del menisco y tiempo de fractura lagrimal (BUT) de 3 y 4 segundos en ojo derecho (OD) y en ojo izquierdo (OI) respectivamente, queratitis punctata difusa, y opacificación corneal epitelial y estromal anterior (fig. 1). En el limbo del OD se apreciaban manchas de Bitöt (fig. 2). Su agudeza visual (AV) era de cuenta dedos a 1 metro en OD y 0,5 en el contralateral. El test de Schirmer fue de $5 \mathrm{~mm}$ en el ojo derecho y de $7 \mathrm{~mm}$ en el izquierdo. Se instauró tratamiento con fluorometolona $0,1 \%$ tópica $\left(\right.$ FML $^{\circledR}$, Allergan SA., Madrid, España) y lágrimas

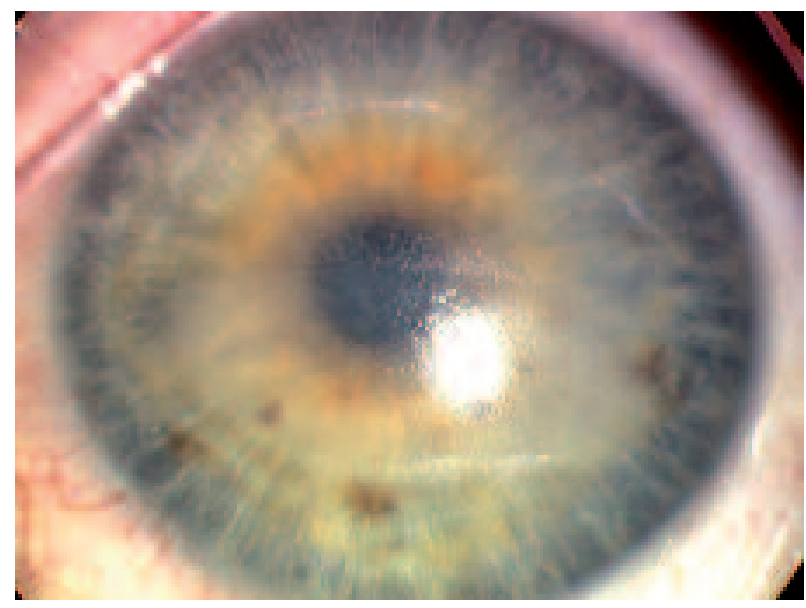

Fig. 1: Caso 1: Aspecto de la superficie corneal donde destaca la alteración de la transparencia y del brillo.

sin conservantes (Viscofresh ${ }^{\circledR} 0,5 \%$, Allergan SA) remitiendo parcialmente la epiteliopatía y recuperando la transparencia corneal (fig. 3), pero sin mejoría a partir de la segunda semana de tratamiento. Se añadió suero autólogo al $20 \%$ cada 4 horas en ambos ojos, con una mejoría gradual. A los 4 meses, la epiteliopatía remitió casi totalmente (fig. 4), con un test de Schirmer de 7 y $8 \mathrm{mmHg}$ en OD y OI respectivamente y una AV corregida final de 0,7 en ambos ojos.

\section{Caso 2}

Mujer de 43 años con dolor en OI y fotofobia. Antecedente de intervención de Scopinaro un año

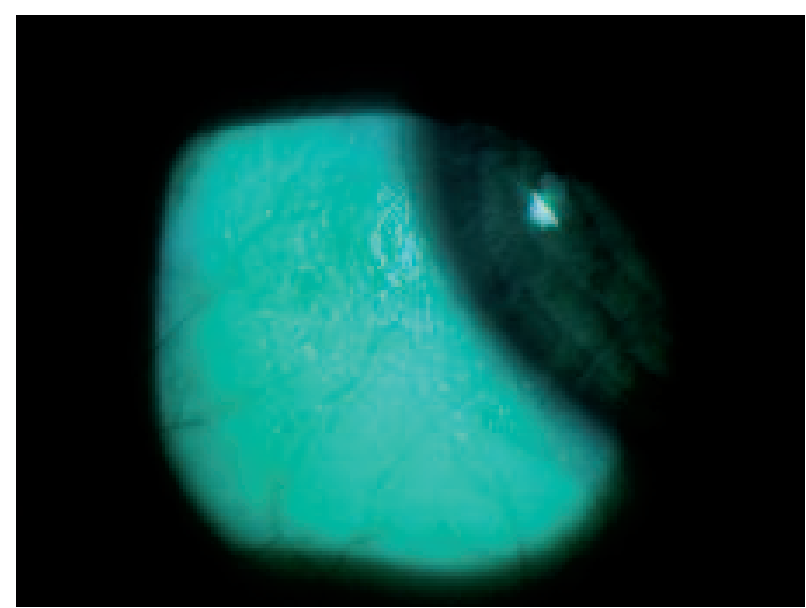

Fig. 2: Caso 1: Manchas de Bitöt del limbo esclerocorneal. 


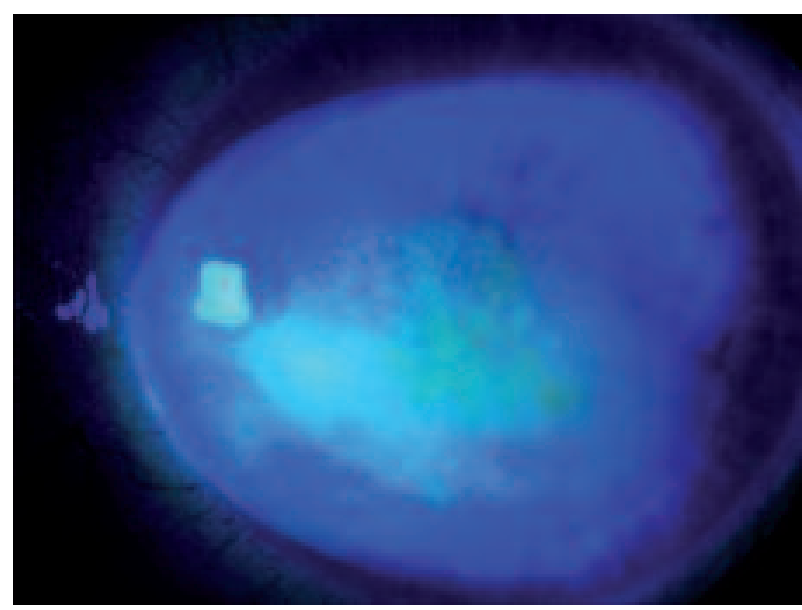

Fig. 3: Caso 1: Tinción con colirio de fluoresceína de la cornea donde se aprecia la mejoría de la perifería.

atrás, cursando un postoperatorio con anemia, varices en extremidades inferiores, hipocalcemia y gonartritis seronegativa.

En la exploración del OI se apreciaba un abceso marginal, epiteliopatía difusa (fig. 5) y queratinización conjuntival (fig. 6). AV corregida de 0,6 en OD y 0,3 en OI. Tras resolverse con ciclopentolato (Ciclopléjico ${ }^{\circledR}$, AlconCusí, S.A., Barcelona, España) y una quinolona tópica (Chibroxín ${ }^{\circledR}$, Thea S.A., Barcelona, España), se apreció que la epiteliopatía no mejoraba pese al tratamiento lubricante (Viscofresh $^{\circledR} 0,5 \%$, Allergan S.A.) manteniendo una AV de $6 / 10$ en OD y 5/10 en OI. Se añadió pilocarpina oral (Salagen ${ }^{\circledR}$, Novartis SA, Barcelona, España) 5 mg cada 6 horas, sin modificación del test de Schir-

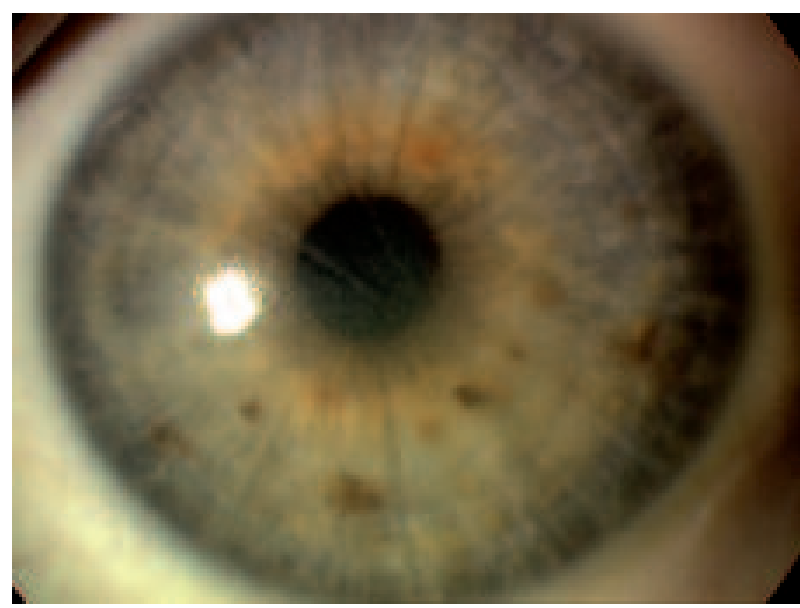

Fig. 4: Caso 1: Aspecto a los 4 meses tras es tratamiento tópico con suero autólogo.

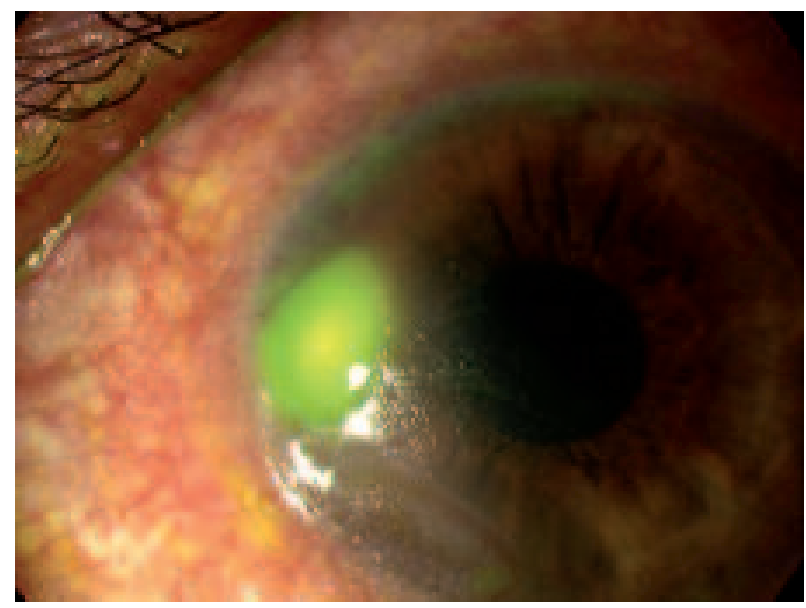

Fig. 5: Caso 2: Abceso corneal que capta la fluoresceína.

mer (2-3 mm en OD y $5 \mathrm{~mm}$ en OI). Al persistir la queratinización conjuntival y la epiteliopatía difusa se añadió suero autólogo al 20\%. En tres semanas aumentó la película lagrimal (Schirmer $5 \mathrm{~mm}$ en OD y $7 \mathrm{~mm}$ en OI) remitiendo la hiperqueratinización conjuntival, con una AV final de 8/10 en AO.

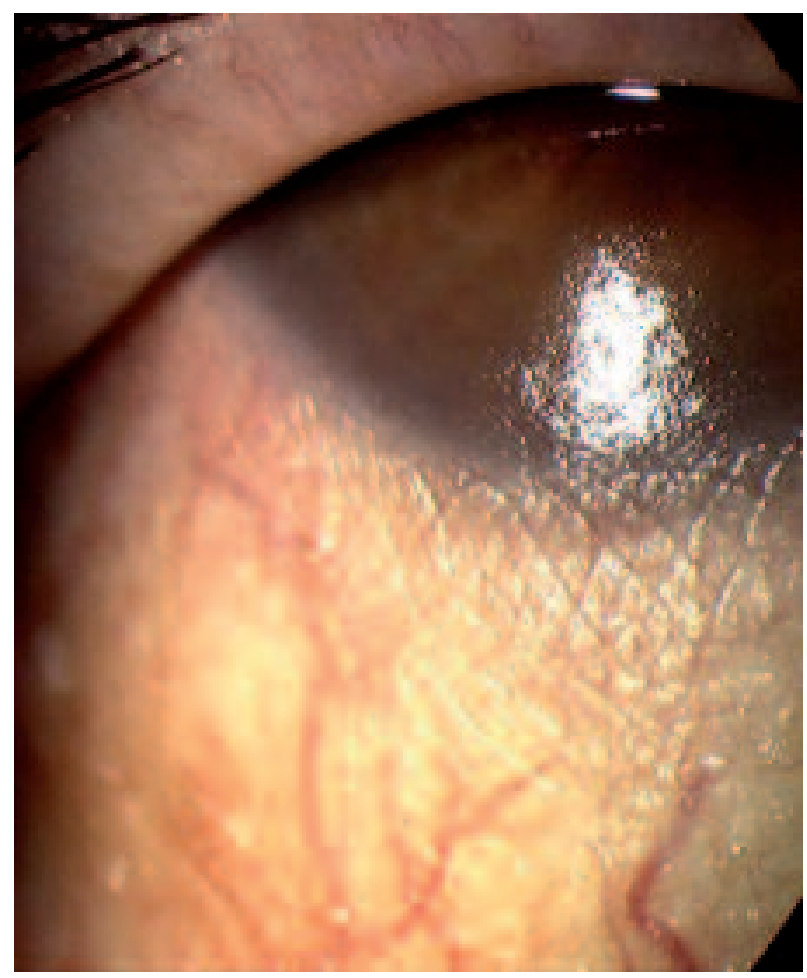

Fig. 6: Caso 2: Alteración del brillo de la superficie ocular y queratinización conjuntival muy evidente. 


\section{DISCUSIÓN}

Los hallazgos observados en estos pacientes, su estado general y su antecedente quirúrgico común indican un síndrome del ojo seco de etiología carencial. Así, la lubricación ocular simple fue insuficiente, siendo la inclusión del suero autólogo lo que determinó una mejoría plausible. Es importante destacar que la involución de los signos y síntomas oculares fue independiente de su estado nutricional, orientando a que el aporte tópico del preparado autólogo proporciona a la superficie ocular todos los nutrientes y factores tróficos necesarios.

Pese al carácter meramente observacional del trabajo, consideramos que el suero autólogo es un buen vehículo para el aporte de retinol a la superficie ocular y que su concentración óptima es del $20 \%$ puesto que, al ser mejor tolerada que la del 30 y $50 \%$, mejora el cumplimiento. Sin embargo, no creemos que sea un buen lubricante y recomendamos añadir lágrimas artificiales.
Puesto la gran incidencia de diferentes grados de desnutrición en los pacientes sometidos a cirugía bariátrica, sugerimos que se incluya un control oftalmológico en su seguimiento.

\section{BIBLIOGRAFÍA}

1. Tseng SC, Maumanee AE, Stark WJ, Maemanee IH, Jensen AD, Green WR, et al. Topical retinoid treatment for various dry-eye disorders. Ophthalmology 1985; 92: 717727.

2. Quaranta L, Nascimbeni G, Semeraro F, Quaranta CA. Severe corneoconjunctival xerosis after biliopancreatic bypass for obesity (Scopinaro's operation). Am J Ophthalmol 1994; 118: 817-818.

3. Speek AJ, van Aagtmaal EJ, Saowakontha S,Schreurs WH, van Haeringen NJ. Fluorometric determination of retinol in human tear fluid using high performance liquid chromatography. Curr Eye Res 1986; 5: 841-845.

4. Tsubota k, Goto E, Shimmura S, Shimazaki J.Treatment of persistent corneal epithelial defect by autologous serum application. Ophthalmology 1999; 106: 1984-1989.

5. Lopez-Garcia JS, Garcia-Lozano I, Rivas L, MartinezGarchitorena J. Aplicaciones del suero autólogo en Oftalmología. Arch Soc Esp Oftalmol 2007; 82: 9-20. 